\title{
Simulation of bulk phases formed by polyphilic liquid crystal dendrimers
}

\author{
J.M. Ilnytsky1, J.S. Lintuvuor 2, M.R. Wilson2 \\ 1 Institute for Condensed Matter Physics of the National Academy of Sciences of Ukraine, \\ 1 Svientsitskii Str., 79011 Lviv, Ukraine \\ 2 Department of Chemistry, University Science Laboratories, University of Durham, \\ South Road, Durham, DH1 3LE, UK
}

Received April 21, 2010, in final form June 8, 2010

\begin{abstract}
A coarse-grained simulation model for a third generation liquid crystalline dendrimer (LCDr) is presented. It allows, for the first time, for a successful molecular simulation study of a relation between the shape of a polyphilic macromolecular mesogen and the symmetry of a macroscopic phase. The model dendrimer consists of a soft central sphere and 32 grafted chains each terminated by a mesogen group. The mesogenic pair interactions are modelled by the recently proposed soft core spherocylinder model of Lintuvuori and Wilson [J. Chem. Phys, 128, 044906, (2008)]. Coarse-grained (CG) molecular dynamics (MD) simulations are performed on a melt of 100 molecules in the anisotropic-isobaric ensemble. The model LCDr shows conformational bistability, with both rod-like and disc-like conformations stable at lower temperatures. Each conformation can be induced by an external aligning field of appropriate symmetry that acts on the mesogens (uniaxial for rod-like and planar for disc-like), leading to formation of a monodomain smectic $\mathrm{A}\left(\mathrm{Sm}_{\mathrm{A}}\right)$ or a columnar (Col) phase, respectively. Both phases are stable for approximately the same temperature range and both exhibit a sharp transition to an isotropic cubic-like phase upon heating. We observe a very strong coupling between the conformation of the LCDr and the symmetry of a bulk phase, as suggested previously by theory. The study reveals rich potential in terms of the application of this form of CG modelling to the study of molecular self-assembly of liquid crystalline macromolecules.
\end{abstract}

Key words: liquid crystals, dendrimers, self-assembling, molecular dynamics

PACS: $02.70 . \mathrm{Ns}, 61.30 . \mathrm{Vx}, 61.30 . \mathrm{Cz}, 61.30 . \mathrm{Gd}$

\section{Introduction}

Polyphilic liquid crystal (LC) molecules are mesogenic molecules composed of segments with different types of interaction. It has proved possible to engineer molecules to contain aliphatic, aromatic, hydrogen bonding and fluorinated segments, all of which can be combined together (in different ways) to produce differing molecular architectures. In one sense the simplest polyphilic mesogens are linear or star-shaped ABC triblock copolymers, which undergo microphase separation to produce interesting mesophase structures [1-4]. However, the range of molecular architectures possible are limited only by the ingenuity of chemists. Recent interesting examples include the use of calamitic bolaamphiphiles with a rigid rod-like aromatic unit, two hydrophilic terminal groups, and a liphophilic or semifluorinated lateral alkyl chain [5 7]; and the use of 'Janus molecules' with two groups of differing mesogens tethered to a molecular core via semi-flexible spacers [8].

A further architectural motif involves the combination of flexible and rigid segments within a mesogen. In combination with different types of interaction, this provides the possibility for polyphilic molecules to change structure on formation of mesophases. Interesting examples include dendrimers, where a central dendritic core has been functionalised by a flexible chain and a terminal mesogenic group [9, 10], multipedal mesogens containing a central octasilsesquioxane core [11] and fullerene containing liquid crystals [12, 13]. Some of the recent exciting work in this area has been summarised in a number of excellent review articles [14 19], which draw parallels between polyphilic thermotropic liquid crystals, block copolymers and self-assembly in amphiphilic and biological systems. 
In principle, computer simulation provides a convenient way of studying the effect of structure on bulk phase behaviour for polyphilic liquid crystals. The effect of small changes in structure can be seen through changes in predicted phase stability and, crucially, simulation can provide a microscopic picture of how changes in structure can direct local packing and orientational ordering. In practice, however, efficacious simulation studies of polyphilic mesogens can be a difficult to achieve. At the atomistic level, simulations of polyphilic systems are often impractical. This is because polyphilic systems are composed of several different fragments, each consisting of a large number of individual atomic sites and ordering of molecules may take place over tens of nanometers requiring a minimum of a few hundred molecules of reasonably high molecular weight. Moreover, the self-assembly of such structures in a simulation can be very slow, requiring hundreds of nanoseconds of dynamics. CG simulations provide a more natural way of studying polyphilic systems. However, even here, large system sizes and long time scales associated with processes such as microphase separation can prove problematic.

In recent years, a number of successful theoretical attempts have been made to study polyphilic liquid crystals. The molecular cubic-block model has been employed to model the self-organization of fullerenomesogens [20, 21]. Progress has also been made with off-lattice coarse-grained models. For example, quite recently, successful attempts to study the phase behaviour of bolaamphiphiles were accomplished using both molecular dynamics [22, 23] and dissipative particle dynamics approaches [24, 25]. Both methodologies used spherical sites and represented rigid parts of a mesogen structure by a combination of spherical sites. As in previous studies of block copolymer mesophases 26 31], such models work quite well because there is strong enthalpic driving force towards microphase separation, which aids in the formation of mesophase structures.

A slightly different class of models attempt to combine spherical and anisotropic potentials. Most notably, Gay-Berne particles have been combined with spherical sites to look at the structure of liquid crystal dimers [32], fullerene containing mesogens [33, 34], main chain [35] and side chain LC polymers [36, 37]; and hard repulsive spherocylinders have been combined with repulsive spheres [38]. Such mixed models are potentially very powerful because they allow for the shape and/or anisotropy of the attractive interactions between mesogenic units to be altered to mimic the different types of interactions found in real mesogens. While quite successful, to date these models have proved relatively slow to equilibrate.

Most recently, the drive for new effective potentials for polyphilic liquid crystals has led to the development of anisotropic soft core potentials [39 42]. Here, the lack of infinite repulsion between molecules at close distances allows for longer time-steps in dynamics simulations and quicker movement of particles through phase space. An important proviso to note is that particles should be repulsive enough to allow for realistic site-site radial distribution functions to be obtained, i. e., should not be able to pass through each other [39]. With this proviso anisotropic soft core potentials provide the possibility for studying complex liquid crystal molecules composed of segments with different types of interaction.

In the current paper, we use anisotropic soft core particles to study the phase behaviour of a polyphilic macromolecule consisting of a model liquid crystalline dendrimer (LCDr) functionalised by terminal mesogenic groups. The coarse-grained model contains three constituent parts, a central dendritic core, flexible spacer groups (characterised by 32 flexible chains bonded to the core), and mesogenic groups terminating each spacer. We use the soft core model of Lintuvuori and Wilson [40], in combination with an efficient parallel simulation program developed by two of the current authors in earlier work [43, 44]. More details on modelling and simulation technique will be given in section 2. In sections 3,4 bulk ordered phases will be obtained with the aid of external fields with appropriate symmetry. We will concentrate on the structure of ordered phases, on their phase transition into an isotropic phase upon heating and on equilibrium conformations of LCDrs in each phase. In section 5 attempts will be made to obtain LCDr self-assembly spontaneously from the isotropic phase by means of temperature decreasing. Conclusions will be given in section 6 . 


\section{Modelling and computational details}

To study self-assembly of the LCDr in the bulk we used a coarse-grained molecular dynamics (CGMD) approach, in which relevant groups of atoms are represented as single particles. The repulsive part of effective potentials can be made softer in this case, in comparison with atom-atom potentials (i. e., $1 / r^{12}$ or $\exp (-a r)$ ), but not as soft as the underlying potentials used in typical dissipative particle dynamics studies [45]. Consequently, one can still use Newtonian dynamics due to sufficient energy exchange in a system via collisions of particles.

The model used in this study is based on the CG LCDr of [38] but makes use of a recently published anisotropic potential, developed by Lintuvuori and Wilson [40], which, in turn, has its origins in the potential of Steuer et al. [46]. Schematically, the model is shown in left frame of figure 1. The LCDr is built from a central sphere, representing the core of the dendrimer, and 32 flexible polymer chains that are (effectively) grafted on its surface but are free to surf on it (freely grafted chains). Each chain is terminated by a terminal spherocylindrical mesogen. The number of chains corresponds to a generation three carbosilane dendrimer. Such a coarse-grained representation for this macromolecule can be justified by earlier findings by Wilson and coworkers [47]. In particular, in solution, the dendritic core was found not to respond significantly to changes in the ordering of an LC solvent, keeping a spherical conformation. However, there was sufficient flexibility in the molecule for the chains with attached mesogenic units to rearrange in response to changes in the orientational and/or translational order of the solvent.
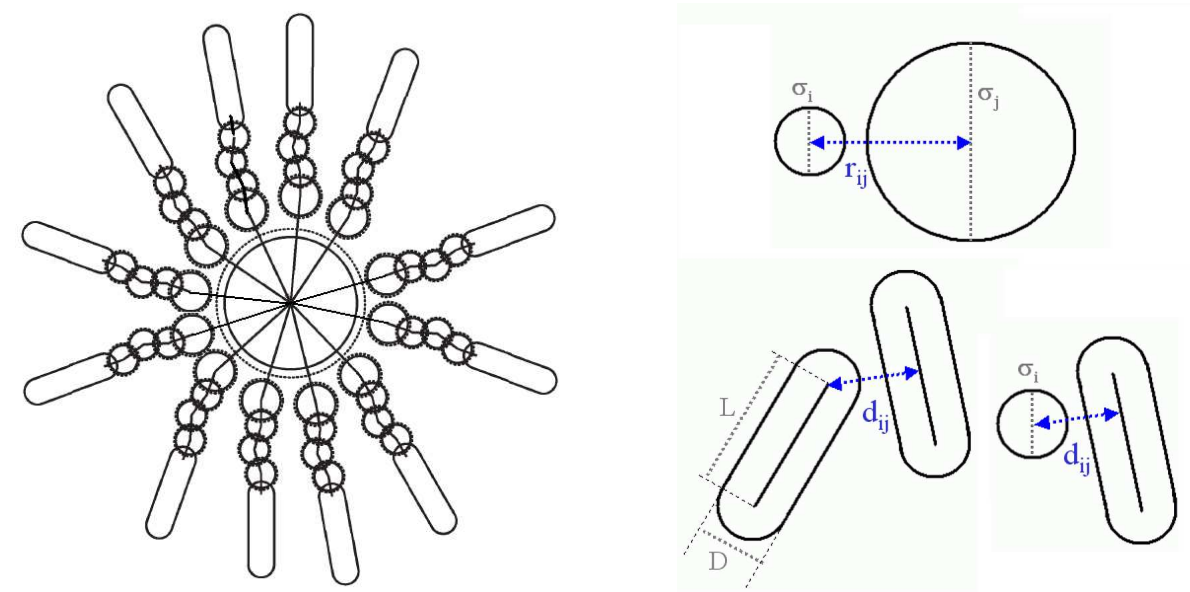

Figure 1. Schematic model for a CG LCDr of generation three (only 12 out of 32 mesogenic branches are shown for the sake of clarity), left frame. Schematic representation showing the definition of sizes and distances for pairs of interacting particles is shown in the right frame.

The model contains three types of spherical sites (designated thereafter as 'sp') and one type of spherocylindrical site ('sc'). The largest, type 1 , spheres represent the dendritic core, type 2 spheres are bonded to them and represent adjacent chemical groups $\mathrm{Si}\left(\mathrm{Me}_{2}\right)-\mathrm{O}-\mathrm{Si}\left(\mathrm{Me}_{2}\right)$, subsequent polymer beads are constructed of the smallest, type 3, spheres, each representing a group of three methylenes: $\mathrm{CH}_{2}-\mathrm{CH}_{2}-\mathrm{CH}_{2}$. The terminal spherocylindrical mesogen represents a cyanobiphenyl group.

The non-bonded pair interaction between all spheres is of soft repulsive type and is represented by a quadratic form

$$
V_{i j}^{\mathrm{sp}-\mathrm{sp}}= \begin{cases}U_{\max }^{\mathrm{sp}-\mathrm{sp}}\left(1-r_{i j}^{*}\right)^{2}, & r_{i j}^{*}<1, \\ 0, & r_{i j}^{*} \geqslant 1,\end{cases}
$$

where $r_{i j}^{*}=r_{i j} / \sigma_{i j}$ is the scaled distance between centers of $i$-th and $j$-th sphere, and usual mixing rules $\sigma_{i j}=\left(\sigma_{i}+\sigma_{j}\right) / 2$ are implied for the spheres with different diameters $\sigma_{i}$ and $\sigma_{j}$ (see right frame of figure 10. In this study the same value of $U_{\max }^{\mathrm{sp}-\mathrm{sp}}$ is used for all combinations of 
interacting spheres. Spherocylinders are of breadth $D$ and of elongation $L / D$ and interact via the soft anisotropic potential of Lintuvuori and Wilson [40]:

$$
V_{i j}^{\mathrm{sc}-\mathrm{sc}}= \begin{cases}U_{\max }^{\mathrm{sc}-\mathrm{sc}}\left(1-d_{i j}^{*}\right)^{2}, & d_{i j}^{*}<1, \\ U_{\max }^{\mathrm{sc}-\mathrm{sc}}\left(1-d_{i j}^{*}\right)^{2}-U_{\mathrm{attr}}^{*}\left(\hat{r}_{i j}, \hat{e}_{i}, \hat{e}_{j}\right)\left(1-d_{i j}^{*}\right)^{4}+\epsilon^{*}, & 1 \leqslant d_{i j}^{*}<d_{\mathrm{c}}^{*}, \\ 0, & d_{i j}^{*}>d_{\mathrm{c}}^{*},\end{cases}
$$

where $d_{i j}^{*}=d_{i j} / D$ is the dimensionless nearest distance between the cores of spherocylinders [48] (see right frame of figure 11), $d_{\mathrm{c}}^{*}$ is the effective cutoff for the attractive interaction that depends on the attractive part of the potential

$$
U_{\mathrm{attr}}^{*}\left(\hat{r}_{i j}, \hat{e}_{i}, \hat{e}_{j}\right)=U_{\mathrm{attr}}^{*}-\left[5 \epsilon_{1} P_{2}\left(\hat{e}_{i} \cdot \hat{e}_{j}\right)+5 \epsilon_{2}\left(P_{2}\left(\hat{r}_{i j} \cdot \hat{e}_{i}\right)+P_{2}\left(\hat{r}_{i j} \cdot \hat{e}_{j}\right)\right] .\right.
$$

The latter depend on orientations $\hat{e}_{i}, \hat{e}_{j}$ of the long axes of spherocylinders and the unit vector $\hat{r}_{i j}$ that connect their centers, as discussed in more detail in [40]. $P_{2}(x)=1 / 2\left(3 x^{2}-1\right)$ is the second Legendre polynomial, whereas energy parameters $U_{\text {attr }}^{*}, \epsilon_{1}$ and $\epsilon_{2}$ are constants defined below. We would like to stress that the inclusion of the attractive contribution to the potential in (2) effectively shifts the region for liquid crystal stability towards elongations $L / D \sim 3$ that are realistic for many typical thermotropic mesogens [40], as compared to the case of purely repulsive interactions, where elongations of $L / D \sim 6-8$ were required for the formation of ordered phases [38].

Mixed nonbonded interactions are evaluated in a way similar to (1)

$$
V_{i j}^{\mathrm{sp}-\mathrm{sc}}= \begin{cases}U_{\max }^{\mathrm{sp}-\mathrm{sc}}\left(1-d_{i j}^{*}\right)^{2}, & d_{i j}^{*}<1, \\ 0, & d_{i j}^{*} \geqslant 1,\end{cases}
$$

where $d_{i j}^{*}=d_{i j} / \sigma_{i j}$ is a dimensionless distance between the center of the $i$-th sphere and the core of the $j$-th spherocylinder (see right frame of figure 1), with the scaling factor $\sigma_{i j}=\left(\sigma_{i}+D\right) / 2$. Parameter $U_{\max }^{\mathrm{sp}-\mathrm{sc}}$ is chosen in this study to be equal to $U_{\max }^{\mathrm{sp}-\mathrm{sp}}$, but values $U_{\max }^{\mathrm{sp}-\mathrm{sc}}>U_{\max }^{\mathrm{sp}-\mathrm{sp}}$ can be used to enhance segregation between sp and sc sites.

Intramolecular interactions for the model include bond and angle interactions terms

$$
V_{\text {bonded }}=\sum_{i=1}^{N_{b}} k_{b}\left(l_{i}-l_{0}^{k}\right)^{2}+\sum_{i=1}^{N_{a}} k_{a}\left(\theta_{i j k}-\theta_{0}\right)^{2},
$$

where $l_{i}$ is the instantaneous separation between the centers of two bonded spheres (or between the center of a sphere and the end of a spherocylinder line segment) for the $i$-th bond, $\left\{l_{0}^{k}\right\}$ is the set of effective bond lengths. Bond angles terms introduce a certain level of stiffness into a CG polymer chain. Following typical choices for similar CG chains, $\theta_{0}=\pi$ is chosen (instead of $\sim 109^{\circ}$ found in atomistic models) and the magnitude of harmonic springs constants $k_{b}$ and $k_{a}$ are lower than their atomistic counterparts. A complete set of the force field parameters used in this study is presented in table 1 . The simulations were carried out with the GBMOLDD program written by two of the current authors [43, 44], which has been extended recently to the case of anisotropic-isobaric ensemble $N P_{x x} P_{y y} P_{z z} T$ in [37].

We should mention that the model, employed in this study, is aimed at reproducing some general features of LCDr, namely, its dendritic architecture, flexibility of terminal chains and liquid crystallinity of terminal mesogens. Chemically detailed coarse graining, that involves a thorough parametrization of the potentials, is required to describe particular dendritic macromolecules in terms of packing densities and phase transition points.

We used relatively simple thermostatting for the system, in particular, a single Nóse-Hoover thermostat [49, 50] was employed for translational and rotational degrees of freedom and, in some cases, velocity rescaling was performed (when rapid heating or cooling was required). The timestep $\Delta t \sim 20$ fs was used for velocity rescaling runs, whereas smaller timesteps $\Delta t \sim 10-15$ fs were required for the runs with the thermostat. To control the pressure in the $N P_{x x} P_{y y} P_{z z} T$ ensemble, 
Table 1. Force field parameters for the CG LCDr model used in this study.

\begin{tabular}{|l|l|r|}
\hline parameter & description & value \\
\hline$\sigma_{1}$ & diameter of sp1 & $21.37 \AA$ \\
$\sigma_{2}$ & diameter of sp2 & $6.23 \AA$ \\
$\sigma_{3}$ & diameter of sp3 & $4.59 \AA$ \\
$D$ & diameter of sc cap sphere & $3.74 \AA$ \\
$L / D$ & elongation of sc & 3 \\
\hline$U_{\mathrm{max}}^{\mathrm{sp}-\mathrm{sc}}$ & maximum repulsive energy, sp-sp & $70 \cdot 10^{-20} \mathrm{~J}$ \\
$U_{\mathrm{max}}^{\mathrm{sp}-\mathrm{sc}}$ & maximum repulsive energy, sp-sc & $70 \cdot 10^{-20} \mathrm{~J}$ \\
$U_{\mathrm{max}}^{\mathrm{sp}-\mathrm{sc}}$ & maximum repulsive energy, sc-sc & $70 \cdot 10^{-20} \mathrm{~J}$ \\
$U_{\mathrm{attr}}^{*}$ & attractive energy parameter, sc-sc & $1500 \cdot 10^{-20} \mathrm{~J}$ \\
$\epsilon_{1}$ & attractive energy parameter, sc-sc & $120 \cdot 10^{-20} \mathrm{~J}$ \\
$\epsilon_{2}$ & attractive energy parameter, sc-sc & $-120 \cdot 10^{-20} \mathrm{~J}$ \\
\hline$m_{1}$ & mass of sp1 & $62.44 \cdot 10^{-25} \mathrm{~kg}$ \\
$m_{2}$ & mass of sp2 & $2.20 \cdot 10^{-25} \mathrm{~kg}$ \\
$m_{3}$ & mass of sp3 & $0.70 \cdot 10^{-25} \mathrm{~kg}$ \\
$m$ & mass of sc & $3.94 \cdot 10^{-25} \mathrm{~kg}$ \\
$I$ & moment of inertia of sc & $6.00 \cdot 10^{-24} \mathrm{~kg} \cdot \AA^{2}$ \\
\hline$l_{1-2}$ & bond length sp1-sp2 & $14.9 \AA$ \\
$l_{2-3}$ & bond length sp2-sp3 & $3.60 \AA$ \\
$l_{3-3}$ & bond length sp3-sp3 & $3.62 \AA$ \\
$l_{3-\mathrm{sc}}$ & bond length sp3-sc & $2.98 \AA$ \\
$k_{b}$ & bond interaction spring constant & $50 \cdot 10^{-20} \mathrm{~J} / \AA^{2}$ \\
\hline$\theta_{0}$ & pseudo-valent angle & $\pi$ \\
$k_{a}$ & angle interaction spring constant & $20 \cdot 10^{-20} \mathrm{~J} / \mathrm{rad}^{2}$ \\
\hline
\end{tabular}

three global separate barostats were used, one for each diagonal component of the pressure $P_{\alpha \alpha}$. All components were fixed at $P_{\alpha \alpha}=P / 3$, where $P$ is the assigned value for the total external pressure. Thermostat and barostat masses $\left(Q\right.$ and $Q_{p}$, respectively) are chosen according to the relations

$$
Q=\left(3\left(N_{\mathrm{sp}}+N_{\mathrm{sc}}\right)+2 N_{\mathrm{sc}}\right) k_{\mathrm{B}} T \tau^{2}, \quad Q_{p}=\left(3\left(N_{\mathrm{sp}}+N_{\mathrm{sc}}\right)\right) k_{\mathrm{B}} T \tau^{2},
$$

where $k_{\mathrm{B}}$ is Boltzmann's factor and $N_{\mathrm{sp}}, N_{\mathrm{sc}}$ are the total numbers of spheres and spherocylinders in a melt, respectively. A time constant was chosen equal to $\tau=3$ ps.

Preliminary runs were aimed at preparing an isotropic melt of the LCDr using the methodology described in reference [38]. Equilibration runs were undertaken at $T=500 \mathrm{~K}$ with a small timestep to relax any internal stress. Initial configurations for further runs were prepared at $P=50 \mathrm{~atm}$ and at $T=400 \mathrm{~K}$ in the isotropic-isobaric $(N P T)$ ensemble, corresponding to an average density of $\rho \sim 0.7 \mathrm{~g} / \mathrm{cm}^{3}$

\section{Smectic phase and the smectic-isotropic phase transition}

As already mentioned above, LCDrs self-assemble into a number of ordered phases depending on the dendrimer generation, chemical composition, temperature and other factors [14 19]. One of the most striking features is the ability of these molecules to adopt distinctly different conformations in different phases [51]. For instance, generation five carbosilane LCDrs most likely adopt rod-like conformations in the smectic phase at lower temperatures and disc-like ones in columnar phases, until the spherically-symmetric conformation is finally adopted in a higher temperature cubic phase 9 .

Previous studies performed on a pseudo-atomistic level, showed that the presence of a nematic solvent promotes rod-like conformations of a generation three LCDr [47]. This effect of the solvent can be interpreted as providing an effective aligning field, which may be mimicked by an external potential

$$
U_{\text {rot }}=-F \cos ^{2}\left(\theta_{i}\right)
$$


where $\theta_{i}$ is the angle between the long axis of the $i$-th spherocylinder and the direction of the field (directed in this study always along the $Z$ axis), $F$ is the maximum in the aligning potential and determines the strength of the applied field $\left(F=f \cdot 10^{-20} \mathrm{~J}, f\right.$ is a reduced field strength, with $f>0$ favouring alignment parallel to the rod-axis and $f<0$ favouring in-plane alignment perpendicular to the rod-axis).

Starting with an isotropic phase at $T=520 \mathrm{~K}$, application of a field with the strength $f=2$ while keeping constant pressure of $P=50 \mathrm{~atm}$ induced the formation of defect free lamellae. Stronger fields induced lamellae with defects, similarly to the case of side chain LC polymers [36, 37]. The phase grown under these conditions was identified as a $\mathrm{Sm}_{\mathrm{A}}$ phase (see below). It was subsequently studied in a series of anisotropic-isobaric runs in the $N P_{x x} P_{y y} P_{z z} T$ ensemble performed at $P=50 \mathrm{~atm}$ and at a range of temperatures $T \in[350 \mathrm{~K}, 650 \mathrm{~K}]$ for durations of between $20 \mathrm{~ns}$ and $40 \mathrm{~ns}$ each.

During these runs we monitored the density of the melt $\rho$ and the order parameter $S_{z}$ of mesogens with respect to the $Z$ axis of the simulation box. It was calculated as

$$
S_{z}=\left\langle P_{2}\left(e_{i}^{z}\right)\right\rangle
$$

where $e_{i}^{z}$ is $Z$-th component of the orientation of the $i$-th mesogen, $P_{2}(x)$ is the second Legendre polynomial and averaging was performed on all mesogens in a melt. The spatial distribution of the molecular mass for the $k$-th molecule was characterised by components of the gyration tensor

$$
G_{\alpha \beta}^{[k]}=\frac{1}{N^{[k]}} \sum_{i=1}^{N^{[k]}}\left(r_{i, \alpha}^{[k]}-R_{\alpha}^{[k]}\right)\left(r_{i, \beta}^{[k]}-R_{\beta}^{[k]}\right), \quad \vec{R}^{[k]}=\frac{1}{N^{[k]}} \sum_{i=1}^{N^{[k]}} r_{i}^{[\vec{k}]},
$$

calculated over $N^{[k]}$ particle centers, $\alpha, \beta$ denote Cartesian axes. When evaluating $G_{\alpha \beta}^{[k]}$ each spherocylinder was replaced by a line of four centers. $G_{\alpha \beta}^{[k]}$ was averaged over the set $\{k\}$ of molecules in a melt and subsequently along the time trajectory in equilibrium phase. Its diagonal elements will be denoted as $G_{x x}, G_{y y}$ and $G_{z z}$. The mean squared radius of gyration is $R_{g}^{2}=G_{x x}+G_{y y}+G_{z z}$, and the asphericity of the molecular mass distribution with respect to the $Z$ axis is given by $a=\left[G_{z z}-\frac{1}{2}\left(G_{x x}+G_{y y}\right)\right] R_{g}^{-2}$. The latter is positive for prolate asphericity and negative for the case of oblate particles.

The simulation data (table 2) show gradual changes upon heating the $\mathrm{Sm}_{\mathrm{A}}$ phase from $T=350 \mathrm{~K}$ to $600 \mathrm{~K}$. From these data, the $\mathrm{Sm}_{\mathrm{A}}$ phase is stable in the range $T=350 \mathrm{~K}-480 \mathrm{~K}(T=350 \mathrm{~K}$ is the lowest temperature being simulated), with a transition to the isotropic phase taking place in the temperature range $T=490 \mathrm{~K}-500 \mathrm{~K}$.

Partial contributions to the potential energy, $V_{\text {total }}$, are listed in table 3. Changes in $V_{\text {total }}$ across the transition region (characteristic bend in the curve with increasing temperature) occur mainly from changes to the sc-sc pair contribution, $V_{\mathrm{sc}-\mathrm{sc}}$. Bonded interactions $V_{\mathrm{bonds}}$ and $V_{\text {angles }}$ are found to grow monotonously with the increase of $T$, whereas $V_{\mathrm{sp}-\mathrm{sp}}$ and $V_{\mathrm{sp}-\mathrm{sc}}$ decrease. These values suggest that in the $\mathrm{Sm}_{\mathrm{A}}$ phase, the flexible chains occupy low energy conformations; and that spheres are fairly tightly packed, with the energy penalty for the high sphere-sphere interaction energy compensated for by strong attractions between mesogens, reflected by low negative values of $V_{\mathrm{sc}-\mathrm{sc}}$.

A snapshot of the $\mathrm{Sm}_{\mathrm{A}}$ phase at $T=470 \mathrm{~K}$ is shown in figure 2, where an ideal lamellar structure is observed with alternating layers of dendrimer scaffold (central sphere and linking chains) and ordered mesogens (see, figure 2, left frame). The two-dimensional arrangement of central cores and mesogens in respective layers is shown in the same figure (right frame). The spatial distribution of the central spheres of each dendrimer was examined by calculating the radial distribution function $g(r)$. To extend the range of distances up to the simulation box dimensions, the box was replicated in space in a $2 \times 2 \times 2$ way. The behaviour of $g(r)$ is very similar in the temperature range $T=350 \mathrm{~K}-470 \mathrm{~K}$ and indicates the presence of two distinctive maxima, one at $r \sim 27 \AA$ for the short-range order of cores within each layer, and another at $r \sim 65 \AA$, which is related to the interlayer distance (figure 3, left frame). The two characteristic distances can be examined 
Table 2. Temperature, $T$, density, $\rho$, nematic order along the $Z$ axis, $S_{z}$, components of the averaged gyration tensor, $G_{\alpha \alpha}$, asphericity, $a$, squared radius of gyration, $R_{g}^{2}$, and type of the ordered phase obtained on heating the $\mathrm{Sm}_{\mathrm{A}}$ phase.

\begin{tabular}{|c|c|r|rrr|r|r|c|}
\hline$T, \mathrm{~K}$ & $\rho, \mathrm{g} / \mathrm{cm}^{3}$ & $S_{z}$ & $G_{x x}, \AA^{2}$ & $G_{y y}, \AA^{2}$ & $G_{z z}, \AA^{2}$ & $R_{g}^{2}, \AA^{2}$ & $a$ & phase \\
\hline 350 & 0.700 & 0.773 & 112.0 & 113.9 & 476.4 & 702.3 & 0.518 & $\mathrm{Sm}_{\mathrm{A}}$ \\
400 & 0.677 & 0.756 & 113.3 & 119.1 & 466.9 & 699.3 & 0.502 & $\mathrm{Sm}_{\mathrm{A}}$ \\
440 & 0.656 & 0.714 & 120.5 & 125.5 & 452.8 & 698.8 & 0.472 & $\mathrm{Sm}_{\mathrm{A}}$ \\
460 & 0.633 & 0.667 & 126.6 & 131.8 & 439.0 & 697.4 & 0.444 & $\mathrm{Sm}_{\mathrm{A}}$ \\
470 & 0.614 & 0.632 & 131.3 & 137.1 & 428.2 & 696.6 & 0.422 & $\mathrm{Sm}_{\mathrm{A}}$ \\
480 & 0.556 & 0.435 & 170.9 & 145.8 & 377.0 & 693.7 & 0.315 & $\mathrm{Sm}_{\mathrm{A}}$ \\
\hline 490 & 0.488 & 0.140 & 200.0 & 209.0 & 281.4 & 690.4 & 0.111 & transition \\
500 & 0.455 & 0.045 & 238.5 & 201.6 & 247.1 & 687.2 & 0.039 & transition \\
\hline 510 & 0.416 & 0.007 & 246.6 & 227.2 & 206.8 & 680.6 & -0.044 & I (cubic-like) \\
520 & 0.404 & -0.003 & 229.6 & 224.2 & 225.4 & 679.2 & -0.002 & I (cubic-like) \\
540 & 0.394 & -0.004 & 228.4 & 227.0 & 222.6 & 678.0 & -0.008 & I (cubic-like) \\
560 & 0.386 & 0.003 & 225.4 & 224.6 & 227.2 & 677.2 & 0.003 & I (cubic-like) \\
600 & 0.375 & 0.002 & 225.9 & 223.6 & 225.7 & 675.2 & 0.001 & I (cubic-like) \\
640 & 0.367 & -0.005 & 226.2 & 223.7 & 223.2 & 673.1 & -0.003 & I (cubic-like) \\
\hline
\end{tabular}

Table 3. Mean potential energies (in $10^{-20} \mathrm{~J}$ units) on heating through the temperature induced $\mathrm{Sm}_{A}-\mathrm{I}$ transition.

\begin{tabular}{|c|rrr|rr|r|c|}
\hline$T, \mathrm{~K}$ & $V_{\mathrm{sp}-\mathrm{sp}}$ & $V_{\mathrm{sc}-\mathrm{sc}}$ & $V_{\mathrm{sp}-\mathrm{sc}}$ & $V_{\text {bonds }}$ & $V_{\text {angles }}$ & $V_{\text {total }}$ & phase \\
\hline 350 & 1049.7 & -23505.3 & 315.0 & 4262.8 & 8148.3 & -9729.5 & $\mathrm{Sm}_{\mathrm{A}}$ \\
400 & 1040.1 & -21902.7 & 338.2 & 4827.5 & 8783.4 & -6913.4 & $\mathrm{Sm}_{\mathrm{A}}$ \\
440 & 1041.5 & -20157.1 & 347.9 & 5294.8 & 9279.9 & -4193.1 & $\mathrm{Sm}_{\mathrm{A}}$ \\
460 & 1004.5 & -18060.2 & 341.6 & 5531.5 & 9432.9 & -1749.7 & $\mathrm{Sm}_{\mathrm{A}}$ \\
470 & 980.3 & -17273.8 & 338.3 & 5636.8 & 9548.7 & -769.7 & $\mathrm{Sm}_{\mathrm{A}}$ \\
480 & 908.5 & -14372.0 & 296.0 & 5775.3 & 9450.8 & 2058.6 & Sm $_{\mathrm{A}}$ \\
\hline 490 & 803.8 & -10026.1 & 239.0 & 5870.7 & 9468.5 & 6355.8 & transition \\
500 & 744.3 & -7063.2 & 222.1 & 5998.7 & 9611.4 & 9513.3 & transition \\
\hline 510 & 647.2 & -3330.1 & 206.7 & 6114.6 & 9831.1 & 13469.4 & I (cubic-like) \\
520 & 630.5 & -2448.2 & 208.6 & 6242.9 & 10016.6 & 14650.4 & I (cubic-like) \\
540 & 623.9 & -1813.4 & 215.1 & 6459.6 & 10332.1 & 15817.4 & I (cubic-like) \\
560 & 626.5 & -1538.7 & 219.6 & 6683.2 & 10693.6 & 16684.2 & I (cubic-like) \\
600 & 643.1 & -1201.2 & 233.2 & 7177.8 & 11376.1 & 18229.0 & I (cubic-like) \\
640 & 664.8 & -1022.0 & 245.5 & 7656.4 & 12063.9 & 19608.6 & I (cubic-like) \\
\hline
\end{tabular}

separately by evaluating pair distribution functions $g_{\mathrm{z}}(r)$ (along the $Z$ axis) and $g_{\mathrm{xy}}(r)$ (in $X Y$ planes). The former allows for the estimation of an interlayer distance at $\sim 59 \AA$. The latter indicates some degree of local (but not long-ranged) positional order within the layers (figure 3 , middle frame), characteristic of a $2 \mathrm{D}$ liquid. Therefore the phase is identified as $\mathrm{Sm}_{\mathrm{A}}$. Snapshot of the frozen $\mathrm{Sm}_{\mathrm{A}}$ phase at $T=350 \mathrm{~K}$ looks virtually identically to the one at $470 \mathrm{~K}$ and is not shown. Plots of $g_{\mathrm{z}}(r)$ indicate a small increase of interlayer spacing $\sim 56 \AA$ in frozen Sm $_{\mathrm{A}}$ phase at $350 \mathrm{~K}$ (see, figure 3, right frame).

It is interesting to note that the volume occupied by the terminal mesogenic units is not sufficient to completely fill mesogen-rich lamellae (figure 2). This situation, that normally never happens in atomistic MD simulations, can be explained by the following two reasons. The first one is connected with the need of precise parametrization of the repulsive interactions in CG model to reproduce packing of underlying atomic model. The second reason is relative rigidity of the chains in our CG model which also might prevent efficient space filling in the melt. We would also predict that it would be possible to fill the voids by adding a small amount of mesogenic solvent with only minimal disruption of the bulk mesophase structure shown in figure 2 .

A typical molecular conformation in the SmAphase is shown in figure 2. Molecules show a 

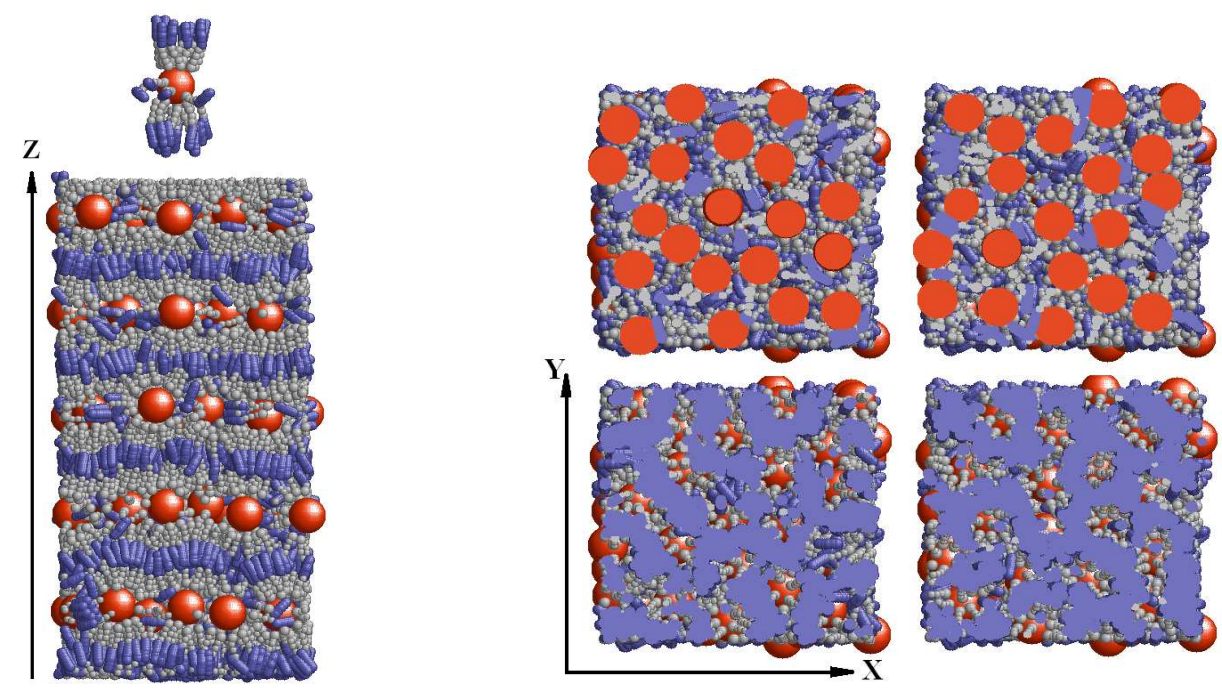

Figure 2. Snapshots of the $\mathrm{Sm}_{\mathrm{A}}$ phase induced by the uniaxial field $(f=2)$ and with subsequent equilibration at $T=470 \mathrm{~K}$ with no field applied. A lamellar structure is shown in the left frame with a typical molecular conformation shown above it. $2 D$ structure of the phase is shown in the right frame via slicing in the middle of core-rich and mesogen-rich lamellae.
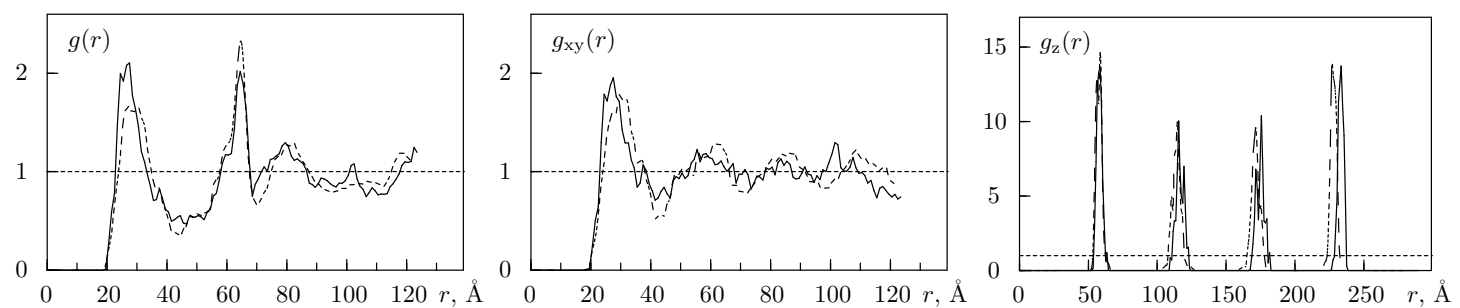

Figure 3. Pair distribution functions for dendritic cores in the $\mathrm{Sm}_{\mathrm{A}}$ phase at $T=350 \mathrm{~K}$ (solid lines) and at $T=470 \mathrm{~K}$ (dashed lines). Radial distribution function $g(r)$ (left frame), 2D radial distribution function $g_{\mathrm{xy}}(r)$ in $X Y$ planes (middle frame) and 1D pair distribution function $g_{\mathrm{z}}(r)$ along the $Z$ axis (right frame).

strong preference for a rod-shaped geometry with uniaxial symmetry, leading to a large anisotropy in the mean gyration tensor $G_{\alpha \alpha}$ and high molecular asphericity (see table 2). Close to the $\mathrm{Sm}_{\mathrm{A}}-\mathrm{I}$ transition the anisotropy decreases (between $T=350 \mathrm{~K}$ and $T=470 \mathrm{~K}$ the asphericity drops by $\approx 18 \%$ ) and fluctuates around zero in the isotropic phase.

At $T>500 \mathrm{~K}$ a macroscopically isotropic, cubic-like phase is observed. A snapshot of the phase at $T=560 \mathrm{~K}$ is shown in figure 4 (left frame). Dendritic cores appear to be arranged on a loosely defined FCC lattice, but the order is smeared by a number of dislocations. This is supported by the form of a radial distribution function $g(r)$ for the molecular cores, which shows liquid-like characteristics. $g(r)$ shape is found to be very similar over a wide range of temperatures $T=500 \mathrm{~K}-640 \mathrm{~K}$ indicating similar structure to the phase throughout this temperature range (see figure 4, right frame). Molecular anisotropy in this cubic-like phase is practically zero (see, table 2 and the single molecule snapshot in figure 44). While individual molecules are spherical in shape (visually resembling spherical micellar structures) the outer layers contain considerable free space, allowing for interdigitation of mesogens from adjacent molecules. This suggests that macroscopically ordered cubic phases might be not achievable for this model dendrimer, as these phases require a denser surface structure to ensure true spherical shape of the LCDr. 


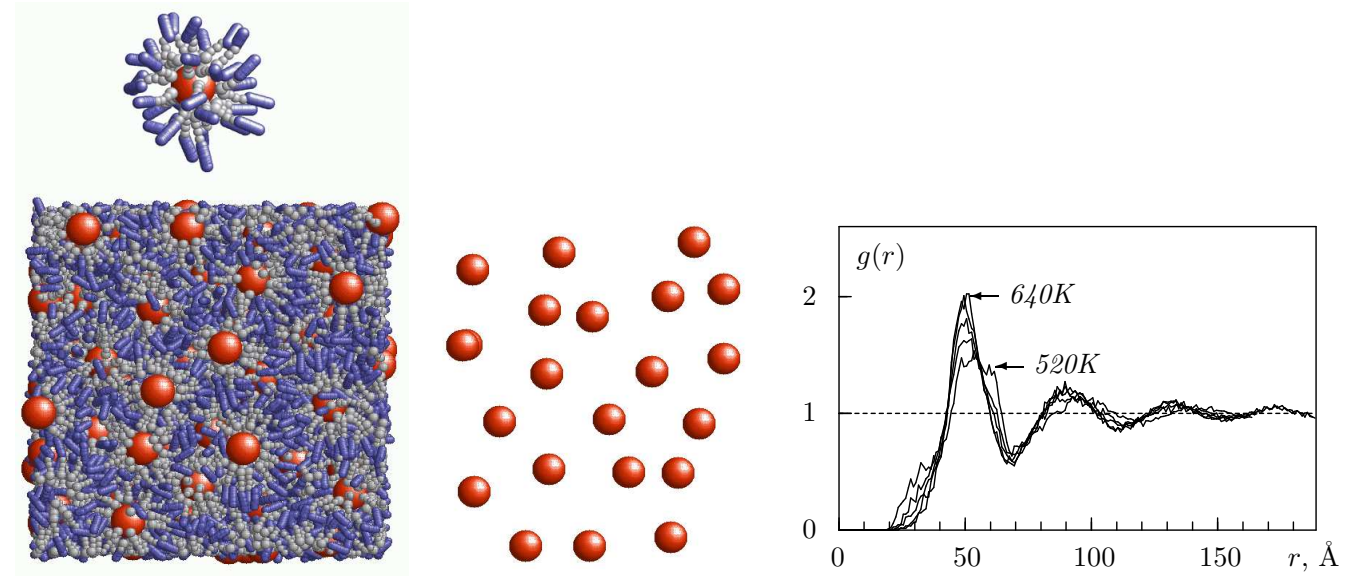

Figure 4. Snapshot of the cubic phase at $T=560 \mathrm{~K}$ (left frame) and its section showing LCDr cores only (middle frame) and the radial distribution function $g(r)$ built for the temperature interval $T=520 \mathrm{~K}-640 \mathrm{~K}$ (right frame).

\section{Columnar phase and the columnar-isotropic transition}

Application of a planar field $(f<0)$ along the $Z$ axis leads to the formation of a Col phase. As for the $\mathrm{Sm}_{\mathrm{A}}$ simulations, well-annealed structures were best achieved through slow growth in the presence of a moderate field $(f=-2)$ at $P=50 \mathrm{~atm}, T \sim 520 \mathrm{~K}$. The resulting Col phase was subsequently studied in a series of isobaric runs performed at $P=50 \mathrm{~atm}$ and at temperatures in the range $T \in[350 \mathrm{~K}, 650 \mathrm{~K}]$. The duration of the runs was similar to those in the case of $\mathrm{Sm}_{\mathrm{A}}$ phase. The temperature dependence of the density, order parameter and gyration tensor of the Col phase between $350 \mathrm{~K}$ and $600 \mathrm{~K}$ are shown in table 4 As observed for the $\mathrm{Sm}_{\mathrm{A}}$ phase, the Col phase is stable in the range $T=350 \mathrm{~K}-490 \mathrm{~K}$ ( $T=350 \mathrm{~K}$ is the lowest temperature simulated), and at $T \sim 500 \mathrm{~K}$ undergoes a transition to the isotropic phase.

Table 4. Temperature dependence of the density $\rho$, nematic order along $Z$ axis $S_{z}$, components of the averaged gyration tensor $G_{\alpha \alpha}$, asphericity $a$, squared radius of gyration $R_{g}^{2}$ and type of the ordered phase obtained for the Col phase.

\begin{tabular}{|c|c|c|c|c|c|c|c|c|}
\hline$T, \mathrm{~K}$ & $\rho, \mathrm{g} / \mathrm{cm}^{3}$ & $S_{z}$ & $G_{x x}, \AA^{2}$ & $G_{y y}, \AA^{2}$ & $G_{z z}, \AA^{2}$ & $R_{g}^{2}, \AA^{2}$ & $a$ & phase \\
\hline 350 & 0.535 & -0.433 & 320.6 & 308.6 & 81.7 & 710.9 & -0.328 & Col \\
400 & 0.524 & -0.403 & 318.5 & 303.7 & 88.0 & 710.2 & -0.314 & Col \\
440 & 0.527 & -0.379 & 313.4 & 299.3 & 94.7 & 707.4 & -0.299 & Col \\
470 & 0.516 & -0.328 & 294.8 & 296.6 & 109.1 & 700.5 & -0.266 & Col \\
480 & 0.518 & -0.302 & 290.7 & 289.2 & 119.0 & 698.9 & -0.245 & Col \\
490 & 0.498 & -0.270 & 277.1 & 288.3 & 127.5 & 692.9 & -0.224 & Col \\
\hline 500 & 0.446 & -0.046 & 237.0 & 235.6 & 212.8 & 685.4 & -0.034 & transition \\
\hline 505 & 0.446 & 0.053 & 254.9 & 179.0 & 252.2 & 686.1 & 0.051 & I (cubic-like) \\
510 & 0.423 & 0.058 & 215.1 & 214.2 & 252.2 & 681.5 & 0.055 & I (cubic-like) \\
515 & 0.408 & 0.009 & 225.1 & 223.7 & 230.7 & 679.5 & 0.009 & I (cubic-like) \\
520 & 0.402 & 0.006 & 226.9 & 223.3 & 228.5 & 678.7 & 0.005 & I (cubic-like) \\
530 & 0.398 & 0.002 & 225.4 & 225.3 & 227.6 & 678.3 & 0.003 & I (cubic-like) \\
540 & 0.394 & 0.001 & 224.0 & 227.3 & 226.1 & 677.4 & 0.001 & I (cubic-like) \\
560 & 0.386 & 0.000 & 225.0 & 226.2 & 225.7 & 676.9 & 0.000 & I (cubic-like) \\
\hline
\end{tabular}

The Col phase exhibits the same trends in potential energy contributions (table 5) as those observed for the $\mathrm{Sm}_{\mathrm{A}}$ phase (table 3). The $\mathrm{Sm}_{\mathrm{A}}$ phase is found to have a lower potential energy than the Col phase at the same temperature. The true thermodynamic stability of each phase 
can only be gauged by free energy calculations. Free energy calculations would be very difficult to achieve for model molecules and model phases of this complexity. While such calculations may not be computationally achievable at the current time, we note that some success has recently been achieved for simple bead-spring block copolymer models [52]. Here, in elegant work by MartínezVeracoechea and Escobedo, chemical potentials were calculated by an expanded ensemble method that gradually inserts or deletes a target chain.

Table 5. Mean potential energies (in $10^{-20} \mathrm{~J}$ units) on heating through the temperature induced Col-I phase transition.

\begin{tabular}{|c|rrr|rr|r|c|}
\hline$T, \mathrm{~K}$ & $V_{\mathrm{sp}-\mathrm{sp}}$ & $V_{\mathrm{sc}-\mathrm{sc}}$ & $V_{\mathrm{sp}-\mathrm{sc}}$ & $V_{\text {bonds }}$ & $V_{\text {angles }}$ & $V_{\text {total }}$ & phase \\
\hline 350 & 1024.9 & -22329.3 & 272.6 & 4284.0 & 7404.8 & -9343.0 & Col \\
400 & 1036.6 & -20170.0 & 280.0 & 4805.0 & 8052.8 & -5995.6 & Col \\
440 & 1005.7 & -17467.1 & 278.1 & 5294.8 & 8602.2 & -2286.3 & Col \\
470 & 940.4 & -14609.8 & 272.0 & 5640.8 & 9040.8 & 1284.2 & Col \\
480 & 931.1 & -13316.5 & 260.7 & 5785.1 & 9172.2 & 2832.6 & Col \\
490 & 863.9 & -11231.1 & 249.7 & 5883.3 & 9398.7 & 5164.5 & Col \\
\hline 500 & 723.6 & -6655.3 & 219.6 & 5995.4 & 9648.2 & 9931.4 & transtition \\
\hline 510 & 651.7 & -3549.6 & 205.4 & 6121.9 & 9831.0 & 13260.4 & I (cubic-like) \\
515 & 623.5 & -2611.3 & 207.5 & 6176.6 & 9920.1 & 14316.4 & I (cubic-like) \\
520 & 630.5 & -2512.9 & 208.8 & 6228.0 & 10015.1 & 14569.5 & I (cubic-like) \\
530 & 616.1 & -1904.9 & 212.5 & 6332.5 & 10190.5 & 15446.7 & I (cubic-like) \\
540 & 617.5 & -1737.3 & 218.7 & 6480.2 & 10357.2 & 15936.3 & I (cubic-like) \\
560 & 631.5 & -1564.7 & 217.8 & 6688.7 & 10702.6 & 16676.0 & I (cubic-like) \\
\hline
\end{tabular}

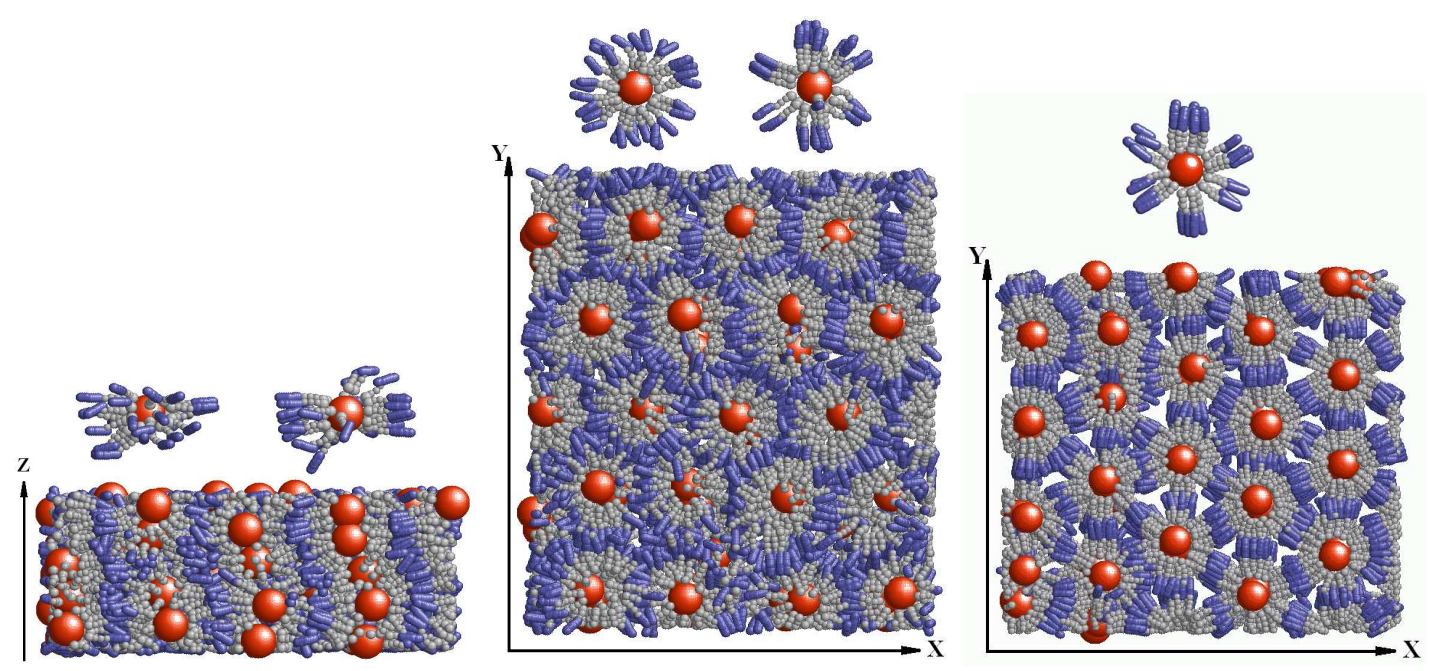

Figure 5. Snapshots of the Col phase (at $T=490 \mathrm{~K}$ ) and frozen Col phase (at $T=350 \mathrm{~K}$ ). A tight vertical arrangement of dendrimers into columns are seen in the side view of the Col phase (left frame), top view of the same phase indicates a hexagonal arrangement of columns (middle frame), typical molecular conformations are shown above each snapshot. Frozen Col phase has highly ordered columnar structure with the LCDrs adopting a hexamer-like conformation (right frame).

Snapshots for the Col phase are shown in figure 5. Both single molecule snapshots and data presented in table 4 indicate a disc-like oblate molecular shape, with $G_{x x} \approx G_{y y}>G_{z z}$ and, subsequently, negative values for asphericity $a$. Similarly to the $\mathrm{Sm}_{\mathrm{A}}$ phase, raising the temperature leads to a reduction in asphericity (between $T=350 \mathrm{~K}$ and $T=490 \mathrm{~K}$ the absolute value for the asphericity decreases by $\approx 32 \%$ ), which can be seen as the reason behind an increase of the 
molecular spacing within the columns at $T=490 \mathrm{~K}$. Similar trends for the decrease in density and nematic order parameter at higher temperatures reflects the move of the melt towards the Col-I transition. The resulting isotropic phase is of the same structure as that formed upon heating the SmAphase (see above).

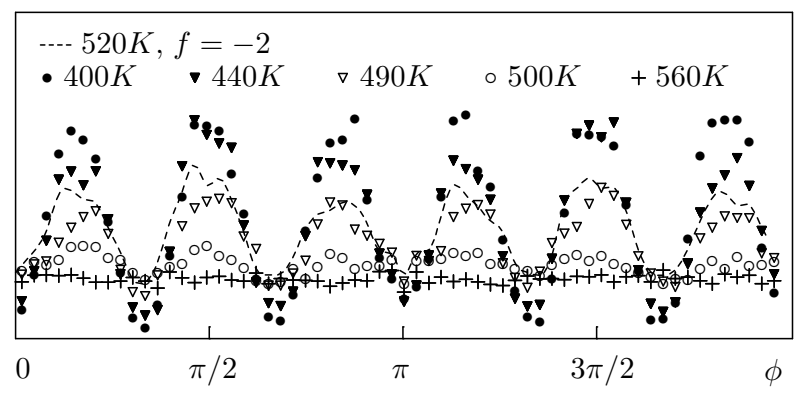

Figure 6. Polar distribution of mesogens centers in $X Y$ plane of oblate shape in Col phase ( $\phi$ is polar angle) at various temperatures. Field induced Col phase is shown as a dashed line.

Let us concentrate on the shape of LCDr in Col phase. It is oblate (as was shown above), but the arrangement of the arms within the 'disc' depends on the temperature. In Col phase at $T=490 \mathrm{~K}$ both uniformly filled discs and hexamer-like discs are found, whereas in frozen Col phase at $T=350 \mathrm{~K}$ the shape is distinctly hexamer-like (see figure 5). One should also mention that in the latter case the arms of the hexamers stacked within each column are strongly correlated spatially. This effect is a result of pure self-assembly, since the sole effect of an external field is promotion of an oblate shape of each LCDr. Polar distribution of the centers of mesogens within the discs indicates that the 'hexamericity' is present to various degree at all temperatures where Col phase is observed (see figure 6). In another set of simulations we checked that the level of the 'hexamericity' found in frozen Col phase at $T=350 \mathrm{~K}$ is independent of the history of the sample preparation. In this respect, the behaviour of our model can be related to that of the TTF-containing hexamers with a flexible disc structure that demonstrate strong ability to form hexagonal columnar phase [53]. We may suggest that some features of the frozen Col phase are related to the peculiarities of the model being employed in this study. One of those is constant (relatively large) stiffness of terminal chains, which may mimick a polymer rather below the glass transition. We may also suggest that with an increase of the number of arms in our model, the hexamer-like discs might give place to uniform discs.
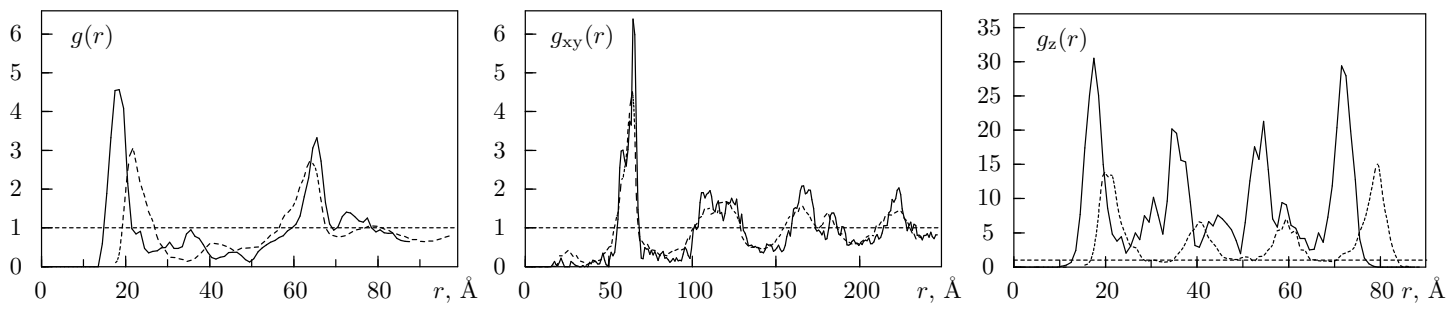

Figure 7. Pair distribution functions for dendritic cores in the Col phase at $T=350 \mathrm{~K}$ (solid lines) and at $T=470 \mathrm{~K}$ (dashed lines): radial distribution function $g(r)$ (left frame), $2 D$ radial distribution function $g_{\mathrm{xy}}(r)$ in $X Y$ planes (middle frame) and $1 D$ pair distribution function $g_{\mathrm{z}}(r)$ along $Z$ axis (right frame).

The structure of Col phase is reflected in the behaviour of the pair distribution functions, shown in figure 7. Hexagonal arrangement of columns is clearly indicated in the form of $g_{\mathrm{xy}}(r)$, while the peaks in $g_{\mathrm{z}}(r)$ allow the distance between dendritic cores within a column to be estimated as $\sim 18 \AA$ for the Col phase at $T=350 \mathrm{~K}$ and $\sim 20 \AA$ at $T=490 \mathrm{~K}$. 

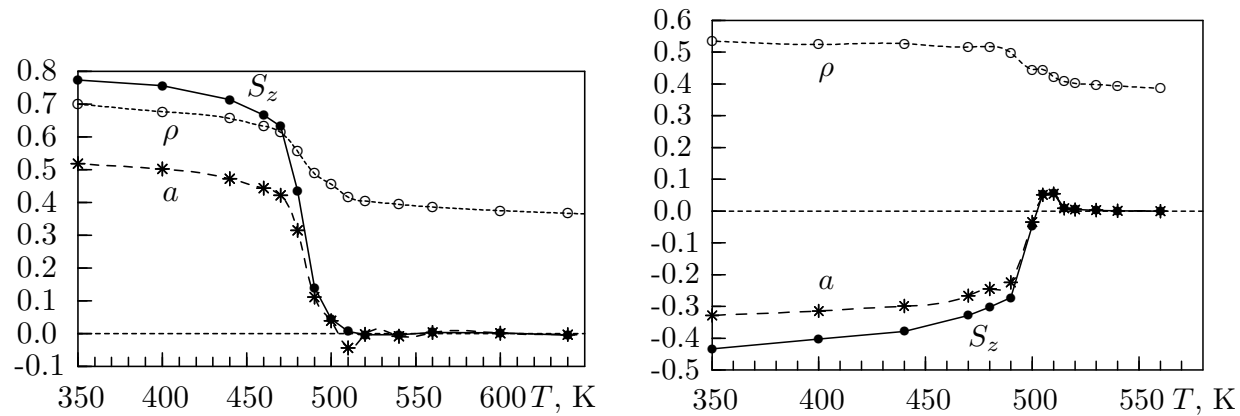

Figure 8. Synchronicity in the changes of molecular asphericity, system density and order parameter at the $\mathrm{Sm}_{\mathrm{A}}-\mathrm{I}$ and $\mathrm{Col}-\mathrm{I}$ phase transitions.

The simulations performed support the view that a strong link exists between the shape of a LCDr and the type of bulk phase exhibited [9, 51]. In particular, rod shapes are compatible with the $\mathrm{Sm}_{\mathrm{A}}$ phase (figure 21), discotic shapes are compatible with Col phases (figure 5) and an isotropic molecular shape is compatible with an isotropic liquid phase. The shape changes prolateto-isotropic or oblate-to-isotropic take place synchronously with the LC-I phase transition, as shown in figure 8 . It is the preferential selection of two groups of energetically similar conformations which makes phases of radically different symmetries possible within the same system. In both cases the transition to the isotropic phase leads to a massive conformational rearrangement reflected in the change in both intramolecular and intermolecular contributions to $V_{\text {total }}$. This conclusion was elegantly predicted in the early theoretical work by Photinos and coworkers [54, 55], and is seen in the current study for the first time for a CG molecular model of this type.

We note in passing that conformational changes are relatively easy to achieve in our model, both because of the CG nature of the polymer chains and due to free grafting of the chains to the surface of the core. Arguably, the latter mimicks generations of LCDr higher than three, which have very flexible scaffolds. It is also worth noting that in the case of some real fifth generation carbosilane LCDrs, Col phases are observed at higher temperatures than smectic phases [9], while in our model, the Col phase thermal stability is similar to that of the $\mathrm{Sm}_{\mathrm{A}}$ phase. In our model, at lower temperatures, we might reasonably expect a Col-Sm $\mathrm{A}$ transition, at the point where the temperature becomes sufficiently low for the chains to straighten, such that the mesogens can no longer fill the space in a planar arrangement around the cores. Unfortunately, at such temperatures, (even for this relatively efficient CG model), phase space sampling is not sufficient to overcome the free energy barrier needed to see a transition to $\mathrm{Sm}_{\mathrm{A}}$ ordering.

Stability of both $\mathrm{Sm}_{\mathrm{A}}$ and Col phases at approximately the same thermodynamical conditions raise an interesting question as to whether direct phase transitions between the two phases are possible by means of some external stimuli (i. e., the applied field). Starting from the spatial arrangement of the Col phase shown in figure 5 , left frame, we performed two further simulations. In the first, a uniaxial field with the strength $f=2$ was applied along the $Z$ axis (aiming at a massive reorientation of mesogens), whereas in the other simulation the field was applied along the $Y$ axis (directed at 'flipping' circularly distributed mesogens into uniaxial 'bunches'). In both cases perfect monodomain $\mathrm{Sm}_{\mathrm{A}}$ phases were formed, but only if the simulation was performed just above the phase transition point, e. g. at $T=520 \mathrm{~K}$. In the case of lower temperatures, simulations were locked into polydomain smectics. Below both transitions the interactions between terminal mesogenic groups strongly lock the melt into one symmetry, and the reassembly into another ordered phase is very slow on the time scale possible in the simulations of the current CG model. We note in passing that many real systems of this type are also extremely viscous; requiring strong electric or magnetic fields to produce uniformly aligned samples [10].

We note that the conformational bistability found here is much harder to simulate than the shape changes seen recently in simulations of an octapedal liquid crystal [40]. The octapedal system was able to self-assemble spontaneously into a smectic phase [40] by conformational rearrangement 
on cooling from an isotropic melt. In the case of an octamer, the far smaller number of arms leads to a complete supression of discotic conformations in which the mesogens are unable to fill the space around a central core.

\section{Spontaneous self-assembly}

As it may be expected from the observations above, with no external field applied, conformational bistability of the LCDr is a serious obstacle towards the formation of a single monodomain phase. This was confirmed by further simulations, in which isotropic melt either cooled or compressed. In the first series of runs an isotropic phase at $520 \mathrm{~K}$ (see table 2) was cooled to $400 \mathrm{~K}$ at a constant pressure of $P=50$ atm using different cooling rates. With cooling rates as slow as $30 \mathrm{~K} / \mathrm{ns}$, frozen, random polydomain structures were observed with relatively small domain sizes. For lower cooling rates, below $12 \mathrm{~K} / \mathrm{ns}$, a clear mixture of $\mathrm{Col}$ and $\mathrm{Sm}_{\mathrm{A}}$ clusters was obtained with

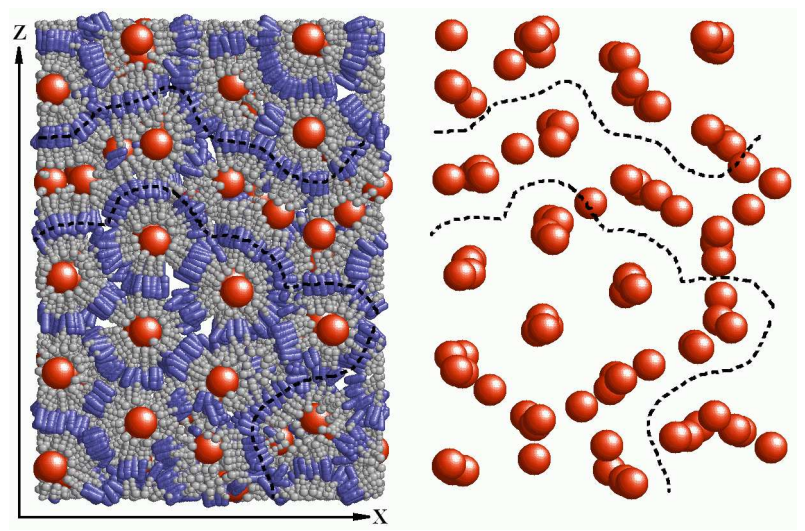

Figure 9. Snapshot of all particles (left frame) and dendritic cores only (right frame) for the spontaneously assembled mixture of smectic and columnar phases. This phase is obtained by isobaric $(P=50 \mathrm{~atm})$ cooling of an isotropic phase from $520 \mathrm{~K}$ down to $400 \mathrm{~K}$ at a rate $12 \mathrm{~K} / \mathrm{ns}$ (for $10 \mathrm{~ns}$ ) and then keeping the constant temperature at $400 \mathrm{~K}$ (for another $15 \mathrm{~ns}$ ). Approximate domain boundaries are shown by dotted contours.

relatively large domain sizes (see figure 9). Prevailance of the Col clusters is revealed in figure 10. with the shape of the pair distribution functions resembling those found for the monodomain Col phase in figure 7
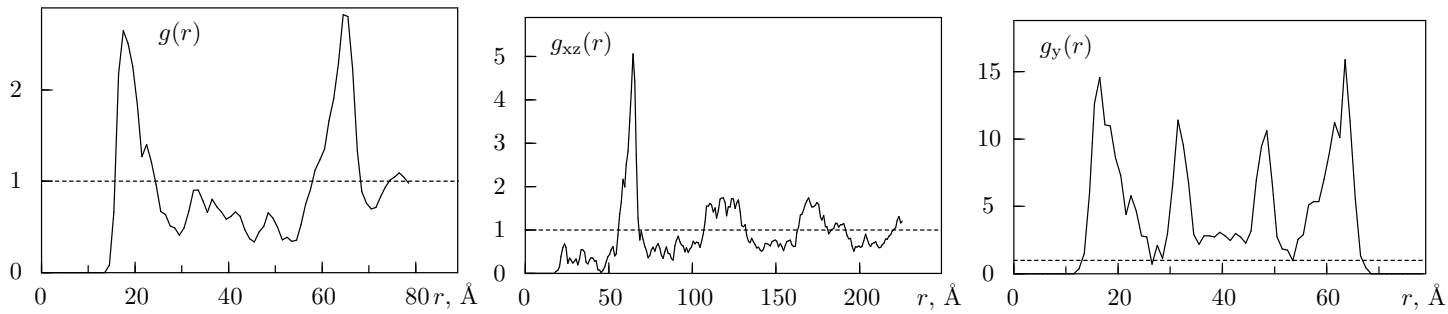

Figure 10. Radial distribution function $g(r)$ (left frame), $2 D$ radial distribution function $g_{\mathrm{xz}}(r)$ in $X Z$ planes (middle frame) and $1 D$ pair distribution function $g_{\mathrm{y}}(r)$ along $Y$ axis (right frame) for a polydomain phase obtained by cooling the melt down to $400 \mathrm{~K}$ (figure 9).

The second set of runs was performed at constant temperature $T=500 \mathrm{~K}$ but at a range of pressures $P=10^{-2}$ atm -80 atm imposed on the melt at the beginning of each run. The evolution of the shape of the radial distribution function $g(r)$ with the increase of the pressure is shown in 

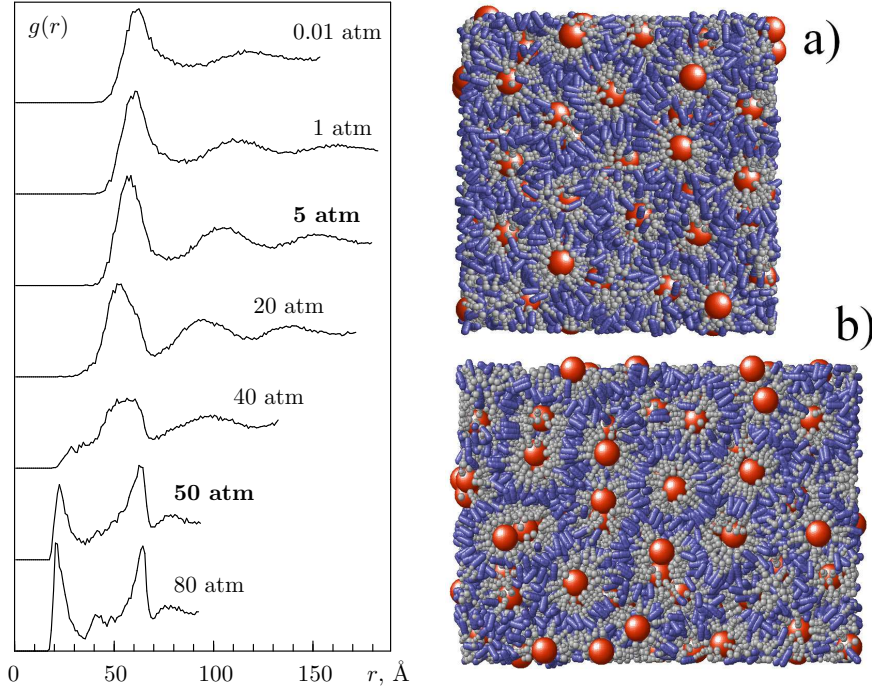

c)

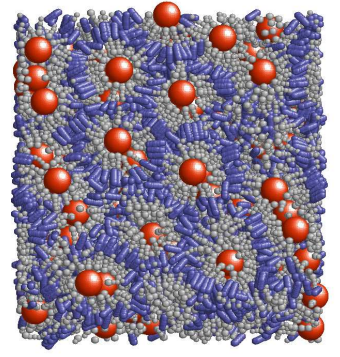

Figure 11. Evolution of the radial distribution function obtained by imposing various pressures to an isotropic melt at constant $T=500 \mathrm{~K}$ (left frame). Snapshot of a cubic phase obtained at $P=5 \mathrm{~atm}(\mathrm{a})$, of a polydomain phase obtained at $P=50 \mathrm{~atm}(\mathrm{~b})$ and of a polydomain phase obtained by slow compressing of the system from $P=20 \mathrm{~atm}$ up to $P=80 \mathrm{~atm}$ with the rate $6 \mathrm{~atm} / \mathrm{ns}$ (c) are shown in right frame.

figure 11 (left frame). At lower pressures $P=10^{-2} \mathrm{~atm}-20 \mathrm{~atm}$ a cubic phase (snapshot (a) in figure 11) is observed with the maxima positions being gradually shifted towards smaller distances as the melt is compressed further. At a threshold pressure $\sim 40$ atm the system starts to undergo a phase transition and at $P>50 \mathrm{~atm}$ a polydomain ordered phase is found with typically two peaks at approximately $21 \AA$ and $64 \AA$. The polydomain phase, shown in figure 11, snapshot (b), is obtained by imposing a pressure of $P=50 \mathrm{~atm}$. As with the temperature induced self-assembly, we also undertook runs with gradual compression. The snapshots, obtained by compression from $P=20 \mathrm{~atm}$ up to $P=80 \mathrm{~atm}$ with various compression rates are very similar to the one shown in figure 9 and demonstrate domains of both $\mathrm{Sm}_{\mathrm{A}}$ and Col phases (the one obtained at the rate $6 \mathrm{~atm} / \mathrm{ns}$ is shown in figure 11, snapshot (c)). The radial distribution functions are also similar to those in figure 10 and are not shown. Therefore, no essential gain towards monodomainity was achieved due to slow compression method.

Therefore, with no symmetry breaker such as an external field, self-assembly of the conformationally bistable LCDr model into a single monodomain phase is difficult to achieve.

\section{Conclusions}

The coarse-grained model for the LCDr exploited in this study is found to exhibit both rod-like and disc-like conformations. The symmetry of this conformational bistability can be broken by application of a suitable external factor, such as the application of an external field or by solvent castings or by surface alignment. In this study we apply a uniform external field, that acts on terminal mesogens and plays the role of a conformational trigger.

In a uniaxial field the dendrimer adopts a rod-like shape and the melt assembles into a smectic A phase on cooling. In the case of a planar field the LCDrs adopt disc-like conformations and columnar phase is formed. In the latter case, the disc is not uniform but of a hexamer form, but this can be attributed to the number of arms in this particular model. The thermal stability of both smectic A and columnar phases is very similar with a sharp transition to an isotropic (cubic-like) phase taking place at $T \sim 500-510 \mathrm{~K}$ for isobaric runs at a pressure of $P=50 \mathrm{~atm}$.

Conformational bistability of the model LCDr prevents spontaneous self-assembly of the isotropic 
melt into one single ordered phase, a polydomain mixture of both smectic A and columnar phase is observed instead. In real systems, the symmetry of shape bistability might be broken not only by external conditions, but also by additional conformational rigidity of the central core (particularly on cooling). The effect of this can be taken into account in future work.

We also note that, for this model, field-induced phase transitions between the $\mathrm{Sm}_{\mathrm{A}}$ and $\mathrm{Col}$ phases are possible only at, or close to, the transition to the isotropic phase. Application of the field below the clearing point leads only to the formation of random domains. We see the reason for this in terms of strong mesogenic interactions at lower temperatures, which effectively produces physical crosslinks that prevent rearrangements of macromolecules.

The simulations demonstrate the power and capabilities of CG approaches and are, to our best knowledge, the first computer simulations of bulk dendritic phases that show macromolecules with switchable shapes that can exist in different bulk ordered phases.

\section{Acknowledgements}

MRW and JSL wishes to thank the EPSRC for the award of a DTA studentship to JSL (20062009). JI thanks S. Sokołowski and M. Schoen for fruitful discussions.

\section{References}

1. Krappe U., Stadler R., Voigtmartin I., Macromolecules, 1995, 28, 4558.

2. Riess G., Progress In Polymer Science, 2003, 28, 1107.

3. Olsen B.D., Segalman R.A., Mat. Sci. Eng. R Rep., 2008, 62, 37.

4. Discher D.E., Eisenberg A., Science, 2002, 297, 967.

5. Kolbel M., Beyersdorff T., Cheng X.H., Tschierske C., Kain J., Diele S., J. Am. Chem. Soc., 2001, 123, 6809 .

6. Cheng X.H., Prehm M., Das M.K., Kain J., Baumeister U., Diele S., Leine D., Blume A., Tschierske C., J. Am. Chem. Soc., 2003, 125, 10977.

7. Cheng X.H., Das M.K., Baumeister U., Diele S., Tschierske C., J. Am. Chem. Soc., 2004, 126, 12930.

8. Goodby J.W., Saez I.M., Chem. Eur. J., 2003, 9, 4869.

9. Ponomarenko S.A., Boiko N.I., Shibaev V.P., Richardson R., Whitehouse I., Rebrov E., Muzafarov A., Macromolecules, 2000, 33, 5549 .

10. Richardson R.M., Barmatov E.B., Whitehouse I.J., Shibaev V.P., Yongjie T., Godhino M.H.F., Mol. Cryst. Liq. Cryst., 1999, 330, 285.

11. Saez I., Goodby J., Liq. Cryst., 1999, 26, 1101.

12. Dardel B., Guillon D., Heinrich B., Deschenaux R., J. Mater. Chem., 2001, 11, 2814.

13. Deschenaux R., Donnio B., Guillon D., New Journal of Chemistry, 2007, 31, 1064.

14. Saez I.M., Goodby J.W., J. Mater. Chem., 2005, 15, 26.

15. Saez I.M., Goodby J.W., Liquid Crystalline Functional Assemblies and Their Supramolecular Structures, 2008, 128, 1.

16. Goodby J.W., Mehl G.H., Saez I.M., Tuffin R.P., Mackenzie G., Auzely-Velty R., Benvegnu T., Plusquellec D., Chem. Comm., 1998, $2057-2070$.

17. Tschierske C., J. Mater. Chem., 2001, 11, 2647.

18. Tschierske C., Curr. Opin. Colloid Interface Sci., 2002, 7, 69.

19. Tschierske C., Chem. Soc. Rev., 2007, 36, 1930.

20. Peroukidis S.D., Vanakaras A.G., Photinos D.J., J. Phys. Chem. B, 2008, 112, 12761.

21. Peroukidis S.D., Vanakaras A.G., Photinos D.J., Soft Matter, 2008, 4, 493.

22. Crane A.J., Martinez-Veracoechea F.J., Escobedo F.A., Muller E.A., Soft Matter, 2008, 4, 1820.

23. Crane A.J., Muller E.A., J. Chem. Phys., 2010, 144, 187.

24. Bates M., Walker M., Soft Matter, 2009, 5, 346.

25. A. Bates M., Walker M., Phys. Chem. Chem. Phys., 2009, 11, 1893.

26. Groot R.D., Madden T.J., J. Chem. Phys., 1998, 108, 8713.

27. Horsch M.A., Zhang Z.L., Glotzer S.C., Phys. Rev. Lett., 2005, 95, 056105.

28. Al Sunaidi A., Den Otter W.K., Clarke J.H.R., Phil. Trans. Roy. Soc. London A, 2004, 362, 1773.

29. Martinez-Veracoechea F.J., Escobedo F.A., J. Chem. Phys., 2006, 125, 104907.

30. Martinez-Veracoechea F.J., Escobedo F.A., Macromol., 2007, 40, 7354. 
31. Ilnytskyi J., Patsahan T., Holovko M., Krouskop P., Makowski M., Macromol., 2008, 41, 9904.

32. Wilson M.R., J. Chem. Phys., 1997, 107, 8654.

33. Orlandi S., Muccioli L., Ricci M., Zannoni C., Soft Matter, 2009, 5, 4484.

34. Sazonovas A., Orlandi S., Ricci M., Zannoni C., Gorecka E., Chem. Phys. Lett., 2006, 430, 297.

35. Lyulin A.V., Al-Barwani M.S., Allen M.P., Wilson M.R., Neelov I., Allsopp N.K., Macromol., 1998, 31, 4626 .

36. Stimson L.M., Wilson M.R., J. Chem. Phys., 2005, 123, 034908.

37. Ilnytskyi J.M., Neher D., J. Chem. Phys., 2007, 126, 174905.

38. Hughes Z.E., Wilson M.R., Stimson L.M., Soft Matter, 2005, 1, 436.

39. Hughes Z.E., Stimson L.M., Slim H., Lintuvuori J.S., Ilnytskyi J.M., Wilson M.R., Comp. Phys. Comm., 2008, 178, 724.

40. Lintuvuori J.S., Wilson M.R., J. Chem. Phys., 2008, 128, 044906.

41. Lintuvuori J.S., Wilson M.R., Phys. Chem. Chem. Phys., 2009, 11, 2116.

42. Berardi R., Zannoni C., Lintuvuori J.S., Wilson M.R., J. Chem. Phys., 2009, 131.

43. Ilnytskyi J., Wilson M.R., Comp. Phys. Comm., 2001, 134, 23.

44. Ilnytskyi J., Wilson M.R., Comp. Phys. Comm., 2002, 148, 43.

45. Groot R., Warren P., J. Chem. Phys., 1997, 107, 4423.

46. Steuer H., Hess S., Schoen M., Physica A, 2003, 328, 322.

47. Wilson M.R., Ilnytskyi J.M., Stimson L.M., J. Chem. Phys., 2003, 119, 3509.

48. Earl D.J., Ilnytskyi J., Wilson M.R., Mol. Phys., 2001, 99, 1719.

49. Nosé S., J. Chem. Phys., 1984, 81, 511.

50. Hoover W., Phys. Rev. A, 1985, 31, 1695.

51. Barbera J., Donnio B., Gimenez R., Guilllon D., Marcos M., Omenat A., Serrano J., J. Mater. Chem., $2001, \mathbf{1 1}, 2808$.

52. Martinez-Veracoechea F.J., Escobedo F.A., J. Chem. Phys., 2006, 125, 104907.

53. Hasegawa M., Enozawa H., Kawabata Y., Iyoda M., JACS Comm., 2007, 129, 3072.

54. Terzis A., Vanakaras A., Photinos D., Mol. Cryst. Liq. Cryst., 1999, 330, 517.

55. Vanakaras A.G., Photinos D.J., J. Mater. Chem., 2001, 11, 2832.

\title{
Моделювання об'ємних фаз у розплаві поліфільних рідкокристалічних дендримерів
}

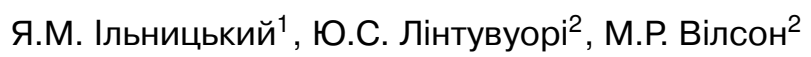 \\ 1 Інститут фізики конденсованих систем НАН України, вул.Свєнціцького, 1, 79011, м.Львів, Україна, \\ 2 Факультет хемії, Університет м. Дарема, Саус роад, Дарем, DH1 3LE, Великобританія
}

\begin{abstract}
Розроблено огрублену модель рідкокристалічного дендримера (РКД) третьої генерації, завдяки чому вперше в літературі вивчено взаємозв'язок між формою рідкокристалічної макромолекули та симетрією макроскопічної фази за допомогою молекулярної динаміки. Модель складається із м'якої центральної сфери, до якої приєднано 32 ланцюжки, кожен із яких закінчується мезогенною групою. Останні взаємодіють за допомогою недавно запропонованого анізотропного потенціалу із м'якою серцевиною Лінтувуорі і Вілсона [J. Chem. Phys, 128, 044906, (2008)]. За допомогою методу огрубленої молекулярної динаміки виконано моделювання розплаву 100 молекул РКД в анізотропноізобаричному ансамблі. Запропонована модель РКД демонструє конформаційну бістабільність, при якій як паличкоподібна, так і дископодібна конформації виявляються стабільними при низьких температурах. Кожна з цих двох конформацій може ініціюватись зовнішнім полем із відповідною симетрією, в результаті в розплаві спонтанно формуються або монодоменна смектична фаза (із паличкоподібних конформацій, ініційованих одновісним полем) або стовпцева фаза (із дископодібних конформацій, ініційованих планарним полем). Обидві фази стабільні приблизно в тому ж температурному інтервалі і при нагріванні переходять в ізотропну кубічну фазу через яскраво виражений фазовий перехід. Спостережено сильний зв'язок між конформацією РКД та симетрією об'ємної фази, на що було вказано раніше в теоретичних роботах. Дослідження виявляє великий потенціал в застосуванні огрубленого моделювання до опису просторової самоорганізації рідкокристалічних макромолекул.
\end{abstract}

Ключові слова: рідкі кристали, дендримери, самоорганізація, молекулярна динаміка 